\title{
Comparative cost-effectiveness of cabozantinib as second-line therapy for patients with advanced hepatocellular carcinoma in Germany and the United States
}

Maximilian Sieg ${ }^{1}$, Michael Hartmann ${ }^{2,3}$, Utz Settmacher ${ }^{4}$ and Habibollah Arefian ${ }^{2,3^{*}}$

\begin{abstract}
Background: Cabozantinib was approved by the European Medicines Agency and the Federal Drug Administration as an option for sorafenib-resistant advanced hepatocellular carcinoma, increasing overall survival and progressionfree survival compared with placebo. We evaluated the cost-effectiveness of cabozantinib in the second-line setting for patients with an advanced hepatocellular carcinoma from the German statutory health insurance perspective compared with an US scenario using US prices.
\end{abstract}

Methods: A Markov model was developed to compare the costs and effectiveness of cabozantinib with best supportive care in the second-line treatment of advanced hepatocellular carcinoma over a lifetime horizon. Health outcomes were measured in discounted life years and discounted quality-adjusted life years. Survival probabilities were estimated using parametric survival distributions based on CELESTIAL trial data. Utilities were derived from the literature. Costs contained drugs, monitoring and adverse events measured in US Dollars. Model robustness was addressed in univariable, scenario and probabilistic sensitivity analyses.

Results: Cabozantinib generated a gain of 0.18 life years ( 0.15 quality-adjusted life years) compared with best supportive care. The total mean cost per patient was $\$ 56,621$ for cabozantinib and $\$ 2064$ for best supportive care in the German model resulting in incremental cost-effectiveness ratios for cabozantinib of $\$ 306,778 /$ life year and $\$ 375$, $470 /$ quality-adjusted life year. Using US prices generated costs of $\$ 177,496$ for cabozantinib and $\$ 4630$ for best supportive care and incremental cost-effectiveness ratios of $\$ 972,049 /$ life year and $\$ 1,189,706 /$ quality-adjusted life year.

\footnotetext{
* Correspondence: Habibollah.Arefian@med.uni-jena.de

${ }^{2}$ Center for Sepsis Control and Care (CSCC), Jena University Hospital, Jena,

Germany

${ }^{3}$ Hospital Pharmacy, Jena University Hospital, Jena, Germany

Full list of author information is available at the end of the article
}

C The Author(s). 2020 Open Access This article is licensed under a Creative Commons Attribution 4.0 International License, which permits use, sharing, adaptation, distribution and reproduction in any medium or format, as long as you give appropriate credit to the original author(s) and the source, provide a link to the Creative Commons licence, and indicate if changes were made. The images or other third party material in this article are included in the article's Creative Commons licence, unless indicated otherwise in a credit line to the material. If material is not included in the article's Creative Commons licence and your intended use is not permitted by statutory regulation or exceeds the permitted use, you will need to obtain permission directly from the copyright holder. To view a copy of this licence, visit http://creativecommons.org/licenses/by/4.0/ The Creative Commons Public Domain Dedication waiver (http://creativecommons.org/publicdomain/zero/1.0/) applies to the data made available in this article, unless otherwise stated in a credit line to the data. 
(Continued from previous page)

Conclusions: Our analysis established that assuming a willingness-to-pay threshold of \$163,371/life year (qualityadjusted life year) for the German model and $\$ 188,559 /$ life year (quality-adjusted life year) for the US model, cabozantinib is not cost-effective compared with best supportive care. Sensitivity analyses showed that cabozantinib was not cost-effective in almost all our scenarios.

Keywords: Hepatocellular carcinoma, Cost-effectiveness, Cabozantinib, Second-line therapy

\section{Background}

Hepatocellular carcinoma (HCC) has a constantly increasing incidence in Germany and the United States, as developed countries, with approximately $6628(8.2 / 100$, 000 inhabitants, Germany) and 24,223 (7.7/100,000 inhabitants, United States) new diagnoses in 2012 [1, 2]. Former hepatitis $\mathrm{B}$ and $\mathrm{C}$ infections, alcoholic cirrhosis and especially the increasing risk of nonalcoholic steatohepatitis are the main drivers of its development [1]. The relative 5-year survival rate remains low at $15 \%$, and curative options such as resection and transplantation are suitable only for locally limited HCC $[3,4]$. Therefore, advances in systemic therapy for advanced HCC are highly necessary.

Since the breakthrough of sorafenib enhanced the treatment of HCC, patients have suffered a lack of second-line options after progression. Brivanib and everolimus failed to improve overall survival (OS) versus placebo in phase III trials [5, 6]. In 2017, regorafenib showed a significant OS prolongation from 7.8 months to 10.6 months versus placebo, leading to approvals by the European Medicines Agency (EMA) and US Food and Drug Administration and its implementation in the European and US market as the first second-line option for systematic HCC therapy [7].

The Federal Joint Committee (GBA) is the German statutory authority that assesses the degree of benefit of newly approved therapies and decides on their reimbursement by the statutory health insurances (SHI). They acknowledged the drug as a nonquantifiable added benefit in the previously approved indication of thirdline treatment for advanced colorectal cancer. As a consequence, the pharmaceutical producer Bayer withdrew regorafenib from German markets because they had identified no opportunity to achieve a sufficient reimbursement amount [8]. Therefore, oncologists could not provide the expensive regorafenib therapy for HCC in Germany, because its costs were no longer reimbursed.

In June 2019, the GBA voted to follow the recommendations of the German Institute for Quality and Efficiency in Health Care (IQWiG) acknowledging a minor added benefit of cabozantinib in the second-line therapy of HCC after progression with sorafenib [9]. Cabozantinib is a tyrosine kinase inhibitor (TKI) that targets tyrosine kinases, such as vascular endothelial growth factor receptor (VEGFR) and hepatocyte growth factor receptor (MET) and it has already been approved as a first-line treatment for advanced medullary thyroid carcinomas and advanced renal cell carcinomas (RCC). This appraisal is based on the findings of Abou-Alfa et al. regarding the CELESTIAL trial results $[10,11]$. Patients treated with cabozantinib showed an OS of 10.2 months compared with 8.0 months with placebo. Progressionfree survival (PFS) was prolonged from 1.9 to 5.2 months [10].

National healthcare systems are facing rising costs to provide new effective therapies. Our aim is to determine the cost-effectiveness of cabozantinib therapy compared with best supportive care (BSC) in patients whose HCC was inadequately treated by sorafenib within the context of the German and the US healthcare system. We considered only BSC as a comparator in the model, as other second-line systemic HCC drugs were not available or reimbursable in Germany or didn't match the target population. Our BSC definition includes health items of monitoring, consulting and adequate treatment of adverse events. The cabozantinib group received equal BSC and cabozantinib. The primary outcome measure is the incremental cost-effectiveness ratio (ICER) quantified in \$ per life year (LY) and \$ per quality-adjusted LY (QALY). We assumed cost-effectiveness thresholds estimated as multiples of the gross domestic product (GDP) per capita deduced from the 3 times GDP per capita rule of the WHO [12]. The impact of uncertainties on the ICER was investigated in sensitivity analyses.

\section{Methods}

\section{General}

The selection of data sources and methods follow the German health economic evaluation recommendations of the IQWiG [13]. Our Markov model was implemented in TreeAge Healthcare Pro 2019 software (TreeAge Pro 2019, R1.1; TreeAge Software, Williamstown, $M A$ ). The data were obtained from published material of the CELESTIAL trial and the submitted GBA dossier of IPSEN Pharma and completed by a literature review on cabozantinib, TKIs and HCC [14]. We considered these sources as adequate clinical effectiveness data, because the CELESTIAL trial met its primary endpoint, was 
sufficiently reported and $48 \%$ of the trial subjects are from Europe and 24\% from the United States or Canada [10].

\section{Target population, setting and perspective}

Our target population in the model was based on the CELESTIAL trial subjects: adult patients with HCC who showed progression under prior sorafenib therapy. The methods of the CELESTIAL trial were described in the published study protocol [15]. In summary, 707 patients were randomized into the cabozantinib group or placebo group and were treated with $60 \mathrm{mg}$ cabozantinib per day or the placebo. The inclusion of patients with ChildPugh A liver function and the exclusion of patients with an uncontrolled clinically significant illness allowed only relatively healthy patients to be included the trial population [15]. We used published data with reference to other TKIs treating HCC if it was necessary to fill data gaps because of identical drug classes and comparable side effects.

$88 \%$ of people in Germany were insured by SHIs in 2015 and $12 \%$ by private health insurances [16]. The US population is covered by multiple overlapping insurance forms: $55.4 \%$ of patients are insured employment-based, $10.8 \%$ use direct-purchase and the public plans Medicare and Medicaid cover 17.8 and $17.9 \%$ [17]. Furthermore, $8.5 \%$ were insured [17]. We chose the perspective of German SHIs for costs induced by cabozantinib therapy and BSC. As a consequence of the diverse US insurance forms and the resulting difficultness to measure exemplary costs, we quantified the chosen health item of the German SHI perspective with adequate US equivalents described in Cost calculation.

\section{Model structure}

A Markov model was constructed to estimate the costs and utility gains of the target population illustrated with
Fig. 1. It consists of three health states representing the natural process of HCC: stable, progressive and dead. All patients started in stable and either stayed at that stage or transitioned to progressive or dead. The transition to progressive represents the CELESTIAL trial progression definition [15]. Once in the progressive stage, patients were able only to either remain in that stage or to die.

\section{Time horizon, cycle length and discounting}

A time lifetime horizon ( 84 months) was selected to simulate a lifetime horizon providing a practically complete cost and utility estimation of a therapy in a palliative setting. A 30-daycycle length was adopted. The discounting of costs and utilities was performed with a rate of $3 \%$, as recommended by the IQWiG [13].

\section{Transition probabilities}

Transition probabilities were deduced from published Kaplan-Meier (KM) curves of the CELESTIAL trial. Parametric distributions were fitted to the KM data for PFS and OS via minimizing the sum of squared residuals to extrapolate from the trial duration to the 84-month horizon. We followed the recommendations of Ishak et al. fitting five parametric distributions to the KM data: exponential, Weibull, Gompertz, log-logistic and lognormal [18]. The best-fitting distribution for all curves was Weibull selected via the sum of squared residuals, Akaike information criterion, Bayesian information criterion and the long-time hazard of the distribution, matching the characteristics of a palliative setting. Goodness of fit values are presented in Table 1 and the detailed transition probabilities and distribution parameters are described in Additional file 1.

\section{Utilities}

Evaluating quality of life (QoL) represents an essential step in determining the effectiveness of novel therapies

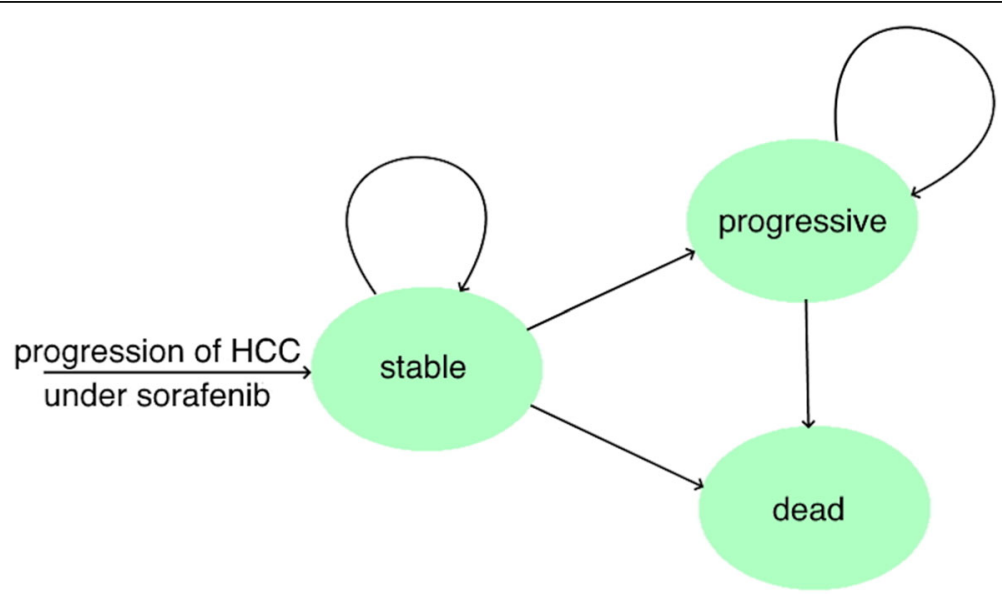

Fig. 1 State transition diagram. HCC = hepatocellular carcinoma 
Table 1 Estimated distribution goodness of fit values of progression-free survival and overall survival

\begin{tabular}{|c|c|c|c|c|c|}
\hline Distribution & Weibull $^{a}$ & Exponential $^{b}$ & Gompertz $^{a}$ & Loglogistic $^{c}$ & Lognormal $^{d}$ \\
\hline \multicolumn{6}{|c|}{ PFS cabozantinib } \\
\hline SSR & 0,012 & 0,026 & 0,016 & 0,021 & 0,015 \\
\hline AlC & -188 & -170 & -180 & -173 & -181 \\
\hline $\mathrm{BIC}$ & -185 & -168 & -178 & -171 & -179 \\
\hline \multicolumn{6}{|c|}{ OS cabozantinib } \\
\hline SSR & 0,010 & 0,032 & 0,016 & 0,019 & 0,014 \\
\hline AlC & -337 & -292 & -317 & -312 & -322 \\
\hline $\mathrm{BIC}$ & -334 & -290 & -314 & -308 & -319 \\
\hline \multicolumn{6}{|l|}{ PFS BSC } \\
\hline SSR & 0,070 & 0,080 & 0,080 & 0,035 & 0,039 \\
\hline AlC & -143 & -142 & -140 & -160 & -158 \\
\hline $\mathrm{BIC}$ & -140 & -140 & -137 & -158 & -155 \\
\hline \multicolumn{6}{|l|}{ OS BSC } \\
\hline SSR & 0,121 & 0,161 & 0,154 & 0,021 & 0,014 \\
\hline $\mathrm{AlC}$ & -208 & -199 & -199 & -273 & -287 \\
\hline $\mathrm{BIC}$ & -205 & -197 & -196 & -270 & -283 \\
\hline
\end{tabular}

PFS progression-free survival, OS overall survival, BSC best supportive care, SSR sum of squared residuals, AIC Akaike information criterion, BIC Bayesian information criterion. ${ }^{a}$ Monotonically increasing. ${ }^{b}$ Constant hazard. ${ }^{c}$ Increasing followed by a gradually decreasing hazard. ${ }^{d}$ Hazard increases to a maximum and then decreases to 0 as time tends to infinity

with high rates of adverse events (AEs). Abou-Alfa et al. published the differences in mean total QALYs during cabozantinib treatment with a significant increase of 0.092 for the entire follow-up using the EQ-5D-5 L QoL questionnaire without reporting total QALYs. The study was limited by low questionnaire return numbers $(82-$ $100 \%$ ) [19]. In our base case, we used 0.76 for stable and 0.68 for progressive. These estimations refer to the findings of Thomsen et al. about QALYs in sorafenibtreated RCC and were used in many cost-effectiveness analyses, including the submission about sorafenib for HCC to the British National Institute for Health and Care Excellence (NICE) [20-22]. The findings of Bruix et al. examining the QALYs of the RESORCE population under regorafenib therapy support these values $(0.76$ under regorafenib and 0.77 under placebo) [23]. As described under Target Population, Setting and Perspective, we found it appropriate to use these values. QALY reductions by AEs were not included into the base case QALYs, because the high AE rates would lead to lower QALYs in the cabozantinib group compared with BSC disagreeing with the QoL findings of Abou-Alfa et al. described above.

\section{Cost calculation}

\section{General}

We considered direct medical costs, including drug, monitoring and $\mathrm{AE}$ costs using $\$$ for easier comparison, converted by purchasing power parities of 2019 with $0.741 € / \$$ and $0.689 € / \$$ as the exchange rates [24]. The frequency and forms of supporting health items were primarily deduced from German clinical practice guidelines and completed by the study protocol recommendations [15].

The German SHI perspective requires health items to be matched with the German diagnosis related groups (DRG) system for hospitalizations and the German Uniform Value Scale catalog for outpatient procedures [25]. DRG values were estimated using the DRG-Research Group Webgrouper. Drug prices and reimbursement amounts were deduced from the pharmacy database Lauer-Taxe of 15th April 2019.

In contrast to Germany, US prescription drug prices have no standardized maximum prices and are affected by multiple rebates and reimbursement programs. We determined the model costs using the US drug price portal GoodRX.com via extracting the average cash prices in April 2019. We estimated physician outpatient fees, other services and hospitalizations using the 2019 physician fee schedule, clinical laboratory fee schedule and Medicare-Severity DRG classifications and software (HCPCS-DRG V1.0 Software) of Centers for Medicare and Medicaid Services and the methods of Tumeh et al. [26].

\section{Costs of cabozantinib medication}

Producers of patented drugs and the SHIs negotiate discounts for every newly approved drug in Germany regarding the acknowledged added benefit by the GBA and the costs of appropriate alternative therapies 
through a process structured by the Pharmaceuticals Market Reorganization Act (AMNOG). If a drug provides multiple indications, such as cabozantinib treating thyroid carcinoma, RCC and HCC, a single discount must represent all indications. The list price of 30 portions of cabozantinib of all dosages amounts to $\$ 8461$, and the current reimbursement amount is $\$ 6841$. Dose modifications were not considered in the model because $40 \mathrm{mg}$ and $20 \mathrm{mg}$ pills produce similar costs in Germany. Therefore, we incorporated the current AMNOG amount of cabozantinib in our German model. The GoodRX.com price for 30 portions of cabozantinib of $60 \mathrm{mg}$ was \$21,581 in April 2019.

According to the CELESTIAL trial protocol, cabozantinib was applied until radiographic progression or discontinuation induced by high-grade AEs [15]. The median time to cabozantinib discontinuation (3.8 months) and the rate of discontinuation owing to AEs related to the cabozantinib trial regime $(16 \%)$ were the only available published data on the time to discontinuation [10]. Regarding the lack of explicit data on the discontinuation rate over time and the minority of toxicityrelated discontinuations, we considered it appropriate to include cabozantinib medication costs in all stable months.

\section{Costs of disease monitoring}

The German HCC guideline and the CELESTIAL study protocol recommend dynamic contrast-enhanced magnetic resonance imaging or computed tomography scan every 2 months as follow-up imaging [15, 27]. The mean costs of both imaging methods were used to match these conditions. The chosen laboratory panel was constructed following the German HCC guidelines on sorafenib for HCC [27].

\section{Costs of treating adverse events}

Our model included treatment-related AEs of every grade reported in $\geq 5 \%$ of patients in either treatment arm in the CELESTIAL trial. We performed a chisquared test to exclude AEs that demonstrated no significant $(p<0.05)$ difference between the two intervention groups to decide whether it was caused by cabozantinib (see Additional file 1). Furthermore, clinically related AEs such as nausea and vomiting were summarized. Required health items included drugs, outpatient services and hospitalizations and were determined along the grade definitions of the Common Terminology Criteria for Adverse Events (CTCAE), Version 4.3. We considered no differences between both comparator groups regarding types, frequencies and costs of the chosen health items. AEs that did not require reimbursable therapy were excluded. The included AE costs were the sum of every grade costs multiplied with its grade incidence.

Adverse events requiring permanent therapy (e. g. hypertension grade 1 requiring antihypertensive drugs) were treated with health items using daily standard dosages with 30 doses per cycle and were matched with an adequate drug compound. The amounted costs were included into all stable cycles until progression. If an adverse events needs a defined treatment with a temporal limit and no need of repetition (e.g. urinary tract infections grade 1 requiring antibiotics for a standardized period), the matching drug compound and its costs were only included into cycle 1 of the state stable. Adverse event grades requiring hospitalizations (e.g. hypertension grade 4, a hypertensive emergency) were matched to an adequate DRG. As we assumed only one hospitalization case per adverse event per patient, we included the costs only in cycle 1 of state stable. All estimated costs per item of both countries are listed in Table 2 below.

\section{Cost-effectiveness thresholds}

Because Willingness-to-pay described through ICERs stays difficult to measure and both national healthcare systems have no cost-effectiveness thresholds, we

Table 2 Monthly Cost Summary

\begin{tabular}{|c|c|c|c|c|}
\hline \multirow{3}{*}{$\frac{\text { Perspective }}{\text { Item }}$} & \multicolumn{4}{|c|}{ Costs in $\$$ per month ${ }^{a}$} \\
\hline & \multicolumn{2}{|l|}{ Germany } & \multicolumn{2}{|l|}{ United States } \\
\hline & Cabozantinib & $\mathrm{BSC}$ & Cabozantinib & BSC \\
\hline Cabozantinib drug & 6841 & 0 & 21,581 & 0 \\
\hline Consultation & 37 & 37 & $110(75)$ & $110(75)$ \\
\hline Laboratory & $27(14)$ & $27(14)$ & $110(55)$ & $110(55)$ \\
\hline Imaging & 93 & 93 & 162 & 162 \\
\hline AE total & $682(139)$ & $213(52)$ & $1673(645)$ & $557(166)$ \\
\hline Diarrhea & $271(13)$ & $48(4)$ & $444(24)$ & $80(8)$ \\
\hline Hand-foot-syndrome & $42(29)$ & $3(2)$ & $385(315)$ & $25(20)$ \\
\hline Fatigue & 15 & 9 & 93 & 56 \\
\hline Nausea and vomiting & $93(45)$ & $64(26)$ & $168(77)$ & $116(44)$ \\
\hline Hypertension & $17(12)$ & 2 & $78(70)$ & 11 \\
\hline Abdominal pain & $24(0)$ & $41(0)$ & $122(0)$ & $187(0)$ \\
\hline Stomatitis & 4 & 1 & 7 & 1 \\
\hline Rash & 16 & 8 & 52 & 27 \\
\hline Thrombocytopenia & $32(0)$ & 0 & $78(0)$ & 0 \\
\hline Dyspepsia & $2(0)$ & $1(0)$ & $8(0)$ & $2(0)$ \\
\hline Hypokalemia & $88(1)$ & $24(<1)$ & $121(3)$ & $33(1)$ \\
\hline Pain in extremity & $2(0)$ & $1(0)$ & $1(0)$ & $<1(0)$ \\
\hline Hypothyroidism & $13(<1)$ & $<1$ & $21(3)$ & $<1$ \\
\hline Hypomagnesemia & $33(0)$ & 0 & $45(0)$ & 0 \\
\hline Urinary tract infection & $26(0)$ & $11(0)$ & $45(0)$ & $19(0)$ \\
\hline
\end{tabular}

The listed $A E$ costs are already incidence-weighted. $A E$ adverse event, $B S C$ best supportive care. ${ }^{a}$ Deviating costs of second and following months in brackets 
estimated cost-effectiveness thresholds as multiples of the GDP per capita deduced from the 3 times GDP per capita rule of the WHO [12]. The primary costeffectiveness threshold was the 3 times GDP per capita per gained LY or QALY and was completed by factor 6 and 9 for a broader overview. Table 3 shows the most current GDPs and the deduced thresholds [28].

\section{Sensitivity analyses \\ Cost analyses}

The impact of the difference between the median PFS (5.2 months) and median time to discontinuation of cabozantinib (3.8 months) was investigated in two ways. First, cabozantinib therapy was applied for only four standardized cycles (months) even without progression. The second approach was subtracting a monthly cabozantinib price if a patient suffered progression to simulate the case of progression 1 month after discontinuation.

\section{Utility analyses}

The high grade of uncertainty regarding QoL under cabozantinib therapy as described in Utilities was investigated through multiple values from findings on QoL regarding $\mathrm{HCC}$ and TKI. Approaches and utilities are presented in Table 5. Despite the findings of Abou-Alfa et al. indicating a QoL gain through cabozantinib, we examined the case of AE-induced disutilities in contrast to our base case. Grade 3/4 incidences of the most important treatment-related AEs were multiplied with disutility values deduced primarily from Kobayashi et al. and complementary to that of Lloyd et al. to calculate reduced QALY values during stable disease [30, 31]. A last method was to use a monthly decreasing utility in a progressive state simulating constantly decreasing QoL after progression.

\section{Univariant and probabilistic sensitivity analyses}

A univariant sensitivity analysis varied major model inputs at defined intervals to determine their impact. Our probabilistic sensitivity analyses were conducted to explore the likelihood of cabozantinib reaching costeffectiveness by varying major model inputs simultaneously in 10,000 iterations. We used a gamma distribution for costs following the recommendations of the
IQWiG to use a distribution with positive skewness and no upper limit [13]. The IQWiG recommended discounting rate borders of 0 and $5 \%$ for sensitivity analyses [13]. These rates were implemented via a beta distribution providing the defined borders and a mean of $3 \%$. A normal distribution offered a simple option to include determined confident intervals of utilities into the probabilistic sensitivity analysis. Detailed distribution data are presented in the Additional file 1.

\section{Results}

\section{Base case results}

Therapy with cabozantinib compared with BSC resulted in a gain of 9.4 weeks or 2.2 months of life (0.18 LYs). Adjusted for QoL, using cabozantinib led to a gain of 0.15 QALYs. Cabozantinib therapy resulted in $\$ 56,621$ and BSC in $\$ 2064$ in Germany and $\$ 177,496$ versus $\$ 4630$ in the US model. The utility gain and costs are itemized in Table 4. The ICERs for cabozantinib versus BSC were $\$ 306,778 / \mathrm{LY}$ and $\$ 375,470 / \mathrm{QALY}$ gained in Germany and the US model resulted in ICERs of $\$ 972$, 049/LY and \$1,189,706/QALY.

\section{Sensitivity analyses}

The results of our univariant and cost-threshold sensitivity analyses are illustrated with tornado diagrams in Figs. 2 and 3. Even with broad variation in the ranges of each parameter, the ICERs remained over the 3 times GDP per capita/LY (QALY) threshold. Monitoring, AEs, discounting and consultation lead to only a minor influence on the ICER in contrast to the cabozantinib price and utility values.

Limiting therapy to 4 months led to an ICER of $\$ 144$, 874/LY (\$177,314/QALY) regarding the German model and $\$ 461,193 / \mathrm{LY}(\$ 564,461 / \mathrm{QALY})$ for the US model and, assuming progression 1 month after cabozantinib discontinuation, to an ICER of $\$ 289,360 / \mathrm{LY}(\$ 354,153 /$ QALY) for the German model and $\$ 897,833 / \mathrm{LY}(\$ 1,098$, 933/QALY) for the US model. The ICERs of multiple testing on QoL are presented in Table 5.

The mean results of our probabilistic sensitivity analysis were illustrated through an ICER scatter plot (Figs. 4 and 5). The probabilities of achieving the determined cost-effectiveness thresholds are presented in Table 6.

Table 3 Estimated cost-effectiveness thresholds

\begin{tabular}{lll}
\hline & Germany & United States \\
\hline GDP per capita in \$ in 2018 & 54,457 & 62,853 \\
Factor & Cost-effectiveness thresholds in \$/LY (QALY) & \\
3 & 163,371 & 188,559 \\
6 & 326,742 & 377,118 \\
9 & 490,113 & 565,677 \\
\hline
\end{tabular}

GDP gross domestic product, $L Y$ life year, $Q A L Y$ quality-adjusted life year 
Table 4 Base case utility and cost breakdown

\begin{tabular}{|c|c|c|c|}
\hline & Cabozantinib & BSC & \\
\hline \multicolumn{4}{|l|}{ Utilities } \\
\hline & Utility gain & Utility gain & Incremental utility \\
\hline Stable LY & 0.646 & 0.341 & 0.305 \\
\hline Progressive LY & 0.505 & 0.632 & -0.127 \\
\hline Total & 1.151 & 0.973 & 0.178 \\
\hline Stable QALY & 0.491 & 0.259 & 0.232 \\
\hline Progressive QALY & 0.343 & 0.429 & -0.086 \\
\hline \multirow[t]{2}{*}{ Total } & 0.834 & 0.698 & 0.146 \\
\hline & Costs in $\$\left(\%^{\mathrm{a}}\right)$ & Costs in $\$\left(\%^{\mathrm{a}}\right)$ & Incremental costs $\left(\%^{\mathrm{a}}\right)$ \\
\hline \multicolumn{4}{|l|}{ Costs Germany } \\
\hline Cabozantinib & $53,018(93.6)$ & $0(0.0)$ & $53,018(97.2)$ \\
\hline Adverse events & $1607(2.8)$ & $375(18.2)$ & $1232(2.3)$ \\
\hline Consultation & $513(0.9)$ & $434(21.0)$ & $69(0.1)$ \\
\hline Laboratory & $202(0.4)$ & $173(8.4)$ & $29(<0.1)$ \\
\hline Imaging & $1281(2.3)$ & $1083(52.5)$ & $198(0.4)$ \\
\hline Total & $56,621(100.0)$ & $2064(100.0)$ & $54,556(100.0)$ \\
\hline \multicolumn{4}{|l|}{ Costs United States } \\
\hline Cabozantinib & $167,288(94.6)$ & $0(0.0)$ & $167,288(96.8)$ \\
\hline Adverse events & $6030(3.8)$ & $1075(56.2)$ & $4955(2.9)$ \\
\hline Consultation & $1075(0.6)$ & $914(43.8)$ & $161(0.1)$ \\
\hline Laboratory & $868(0.3)$ & $751(0.0)$ & $117(0.1)$ \\
\hline Imaging & $2236(0.7)$ & $1890(0.0)$ & $346(0.2)$ \\
\hline Total & $177,496(100.0)$ & $4630(100.0)$ & $172,866(100.0)$ \\
\hline
\end{tabular}

BSC best supportive care, $L Y$ life years, $Q A L Y$ quality-adjusted life years. Total values may be affected by rounding errors. ${ }^{a} \%$ of total

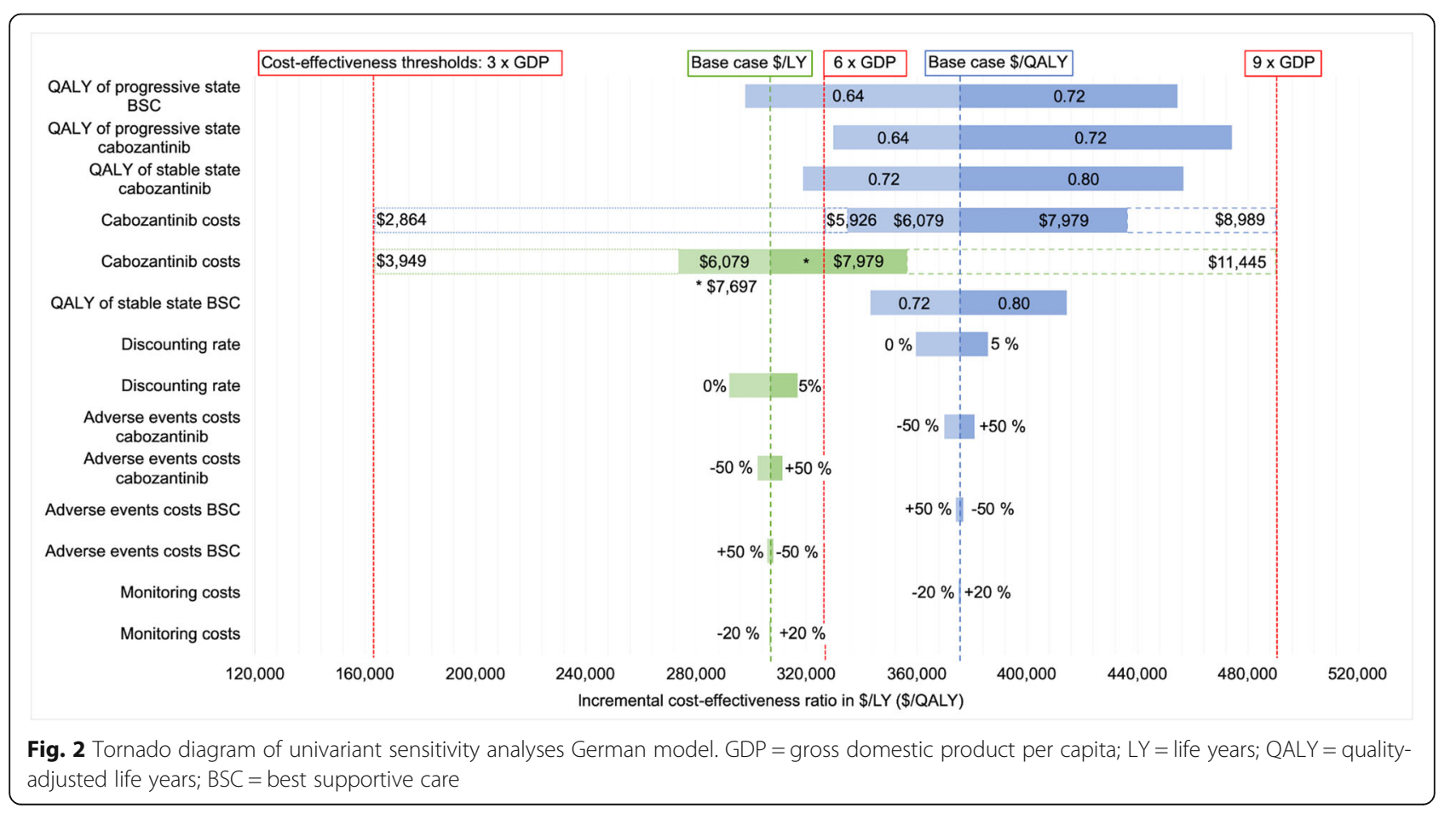




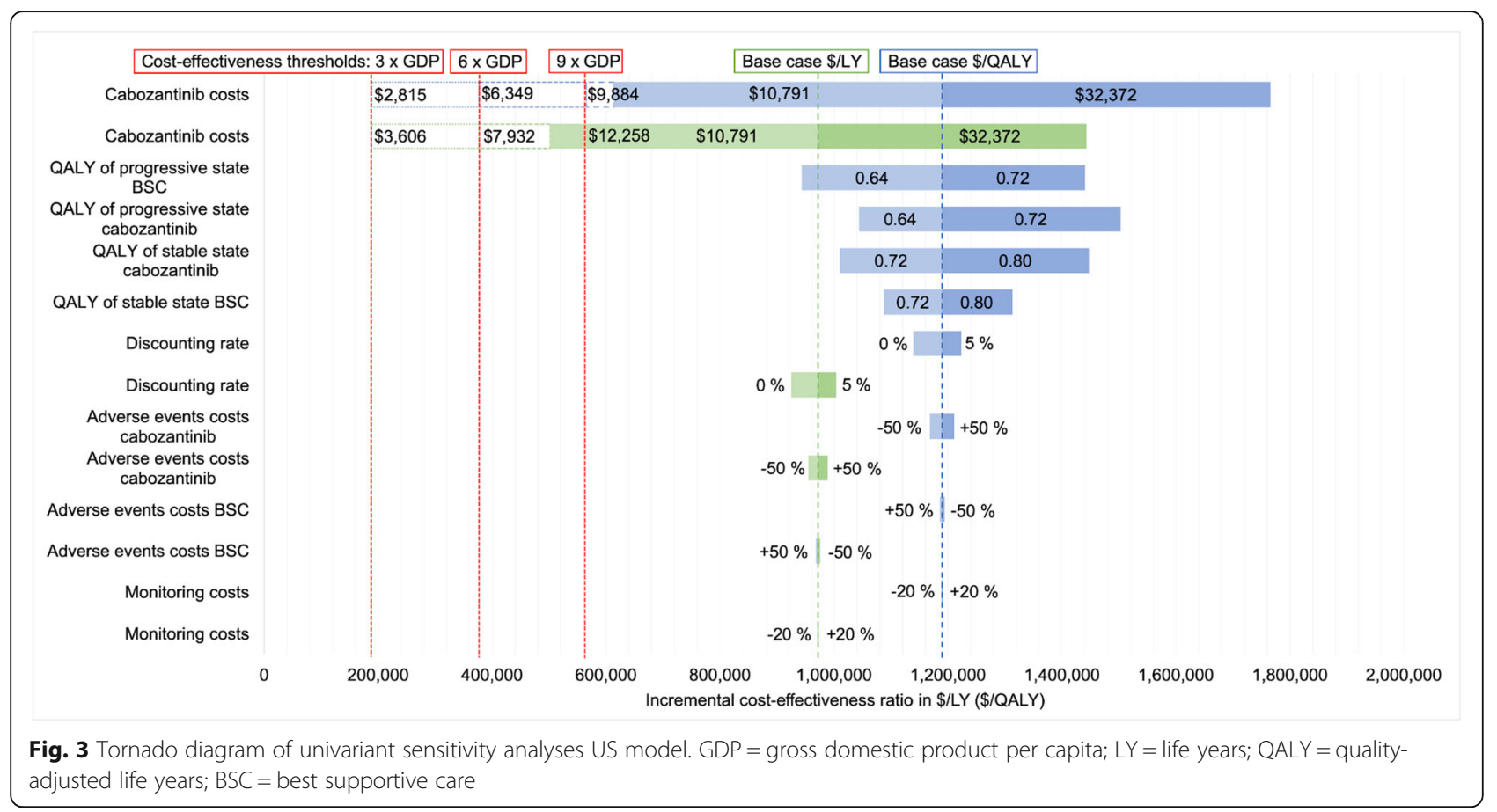

\section{Discussion}

Treating HCC after failed sorafenib therapy is effective in our base case with a mean survival gain of 2.2 months versus BSC, supporting the findings of AbouAlfa et al. and the IQWiG rating of the survival benefit as considerably downgraded to minor owing to the high AE rate [9]. All our scenarios and iterations of our probability analyses showed superior effectiveness and much higher costs of cabozantinib therapy compared with BSC. The base case ICERs were not costeffective using the 3 times GDP per capita/LY (QALY) thresholds of both models. Cabozantinib drug proportion represented the main cost driver generating over $90 \%$ of all costs and showed that combined with QoL utilities, it had the largest impact on ICER in the univariant sensitivity analysis. In addition, our cost-threshold analysis indicates that cabozantinib requires high rebates, reducing its list price to be cost-effective.

The high rates of AEs during placebo therapy underline the massive disease burden of HCC even in populations with Eastern Cooperative Oncology Group score 0 or 1 performance status. In our analysis, AEs induced an increment of \$1232 (Germany) and \$4955 (US) between the groups but represented, together with other additional costs, less than $10 \%$ of the treatment-related costs.

Our analysis has considerable limitations, which we sought to address through our sensitivity analyses. First, a fundamental limitation of our study was the reliance on published data from the CELESTIAL trial. In 2016, the average age of $\mathrm{HCC}$ onset was approximately 70 in Germany [3]. Therefore, the real-world effectiveness of cabozantinib might be worse. Further, the lack of suitable QoL data was solved by testing multiple approaches, but

Table 5 Utility sensitivity analysis

\begin{tabular}{|c|c|c|c|c|c|c|c|}
\hline & \multicolumn{4}{|c|}{ Utilities } & \multirow{3}{*}{$\begin{array}{l}\text { Incremental } \\
\text { effectiveness } \\
\text { in gained } \\
\text { QALYs }\end{array}$} & \multicolumn{2}{|c|}{ ICER in \$/QALY } \\
\hline & \multicolumn{2}{|c|}{ Cabozantinib } & \multicolumn{2}{|l|}{ BSC } & & \multirow{2}{*}{$\begin{array}{l}\text { German } \\
\text { model }\end{array}$} & \multirow{2}{*}{$\begin{array}{l}\text { US } \\
\text { model }\end{array}$} \\
\hline & stable & $\overline{\text { prog }}$ & stable & $\overline{\text { prog }}$ & & & \\
\hline Base Case $[20,21,23]$ & 0.760 & 0.680 & 0.760 & 0.680 & 0.15 & 375,470 & $1,189,706$ \\
\hline Base Case increased by findings of Abou-Alfa et al. [19] & 0.852 & 0.680 & 0.760 & 0.680 & 0.20 & 266,479 & 844,359 \\
\hline Cabozantinib as first-line in advanced RCC [29] & 0.817 & 0.777 & 0.817 & 0.777 & 0.15 & 362,825 & $1,149,640$ \\
\hline Base case adjusted by AE caused disutilities ${ }^{a}[30,31]$ & 0.728 & 0.680 & 0.751 & 0.680 & 0.13 & 427,215 & $1,353,665$ \\
\hline Base case with constantly decreasing utility after progression ${ }^{\mathrm{b}}$ & 0.760 & 0.680 & 0.760 & 0.680 & 0.14 & 387,439 & $1,227,631$ \\
\hline
\end{tabular}

prog progressive, BSC best supportive care, $Q A L Y$ quality-adjusted life years, ICER incremental cost-effectiveness ratio, $A E$ Adverse event. ${ }^{\text {a }}$ The detailed estimations are presented in the Additonal file $1 .{ }^{b}$ Utilities decreased 0.005 per month for both groups 


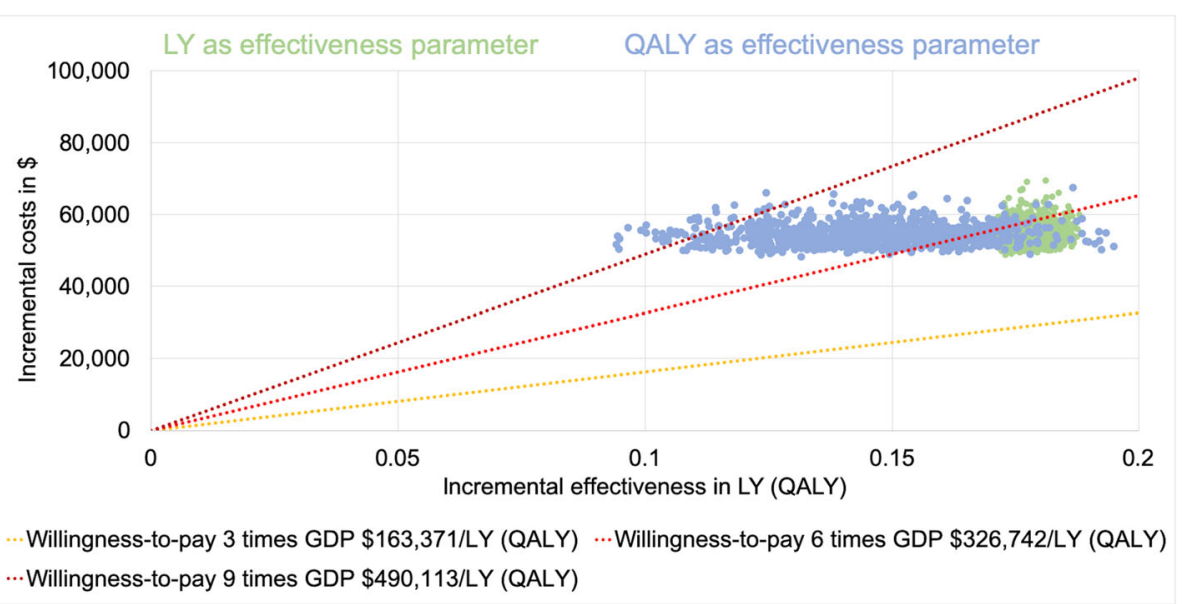

Fig. 4 ICER scatter plot German model. GDP = gross domestic product per capita; LY = life year; QALY = quality-adjusted life year. Only the first 1000 iterations were plotted for clarity

all examined combinations were not cost-effective. The relevance for therapy decisions, e.g., between cabozantinib or regorafenib, and the massive impact on costeffectiveness indicate the need for more standardized QoL reporting in large intervention trials. Ultimately, the practical value for decision makers of our threshold is very unclear, as the GBA has other approaches for assessing costeffectiveness, and willingness-to-pay remains difficult to measure [32]. Assuming higher cost-effectiveness thresholds led especially in the German model to increased probabilities that cabozantinib is a cost-effective therapy.

IPSEN Pharma refused to submit a cost-effectiveness analysis to the NICE about cabozantinib for HCC because no scenario reached the cost-effectiveness thresholds [33]. In July 2016, the National Health Service (NHS) England established the Cancer Drugs Fund to provide early access to new therapies with unclear effectiveness, but cabozantinib for $\mathrm{HCC}$ is not in the current list for January 2020, meaning no reimbursement of cabozantinib [34, 35]. There are two cost-effectiveness analyses of second-line therapy for HCC from the US payer perspective with non-cost-effective ICERs ranging from $\$ 469,374 / \mathrm{QALY}$ to $\$ 1,040,675 / \mathrm{QALY}$ [36-38]. These findings and our US pricing scenario match the development of the United States financing the most expensive healthcare system of all countries of the Organisation for Economic Co-operation and Development with expenditures of $16.9 \%$ of the gross domestic product (Germany 11.2\%) [39]. The high difference ICERs between the US and German scenarios is mostly caused by US drug prices, which are often much higher than German prices (Table 2). Facing various new patented

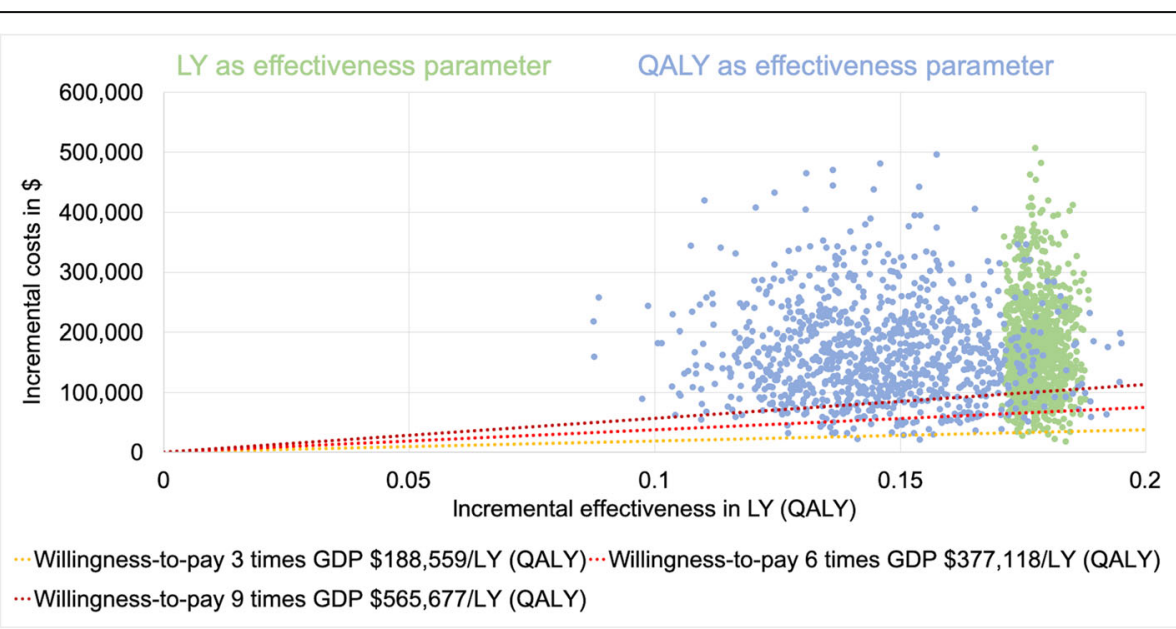

Fig. 5 ICER scatter plot US model. GDP = gross domestic product per capita; LY = life year; QALY= quality-adjusted life year. Only the first 1000 iterations were plotted for clarity 
Table 6 Probability of achieving the cost-effectiveness thresholds

\begin{tabular}{|c|c|c|c|c|}
\hline \multirow{3}{*}{$\begin{array}{l}\text { cost- } \\
\text { effectiveness } \\
\text { threshold in } \\
\text { GDP per } \\
\text { capita/LY } \\
\text { (QALY) } \\
\end{array}$} & \multicolumn{4}{|c|}{ Probability of achieving the cost-effectiveness threshold in percent } \\
\hline & \multicolumn{2}{|l|}{ Germany } & \multicolumn{2}{|c|}{ United States } \\
\hline & LY & QALY & LY & QALY \\
\hline 3 & 0 & 0 & 0.5 & 0.2 \\
\hline 6 & 87.3 & 85.6 & 5.6 & 4.3 \\
\hline 9 & 100.0 & 96.4 & 19.2 & 11.7 \\
\hline
\end{tabular}

GDP gross domestic product, $L Y$ life year, $Q A L Y$ quality-adjusted life year

drugs, German lawmakers set maximum prices and statutory rebates via the AMNOG to limit annual drug spending increases [40]. In consequence, the prescription drug price index decreased 15\% from 2004 to 2018, estimated after statistics of the AOK Research Institute [41]. In contrast, the US prescription drug price index increased 56\% in the same period but decreased in 2019 as the first time since 1974, estimated after statistics of the US Bureau of Labor Statistics [42].

Regorafenib, with its similar survival outcomes, was investigated by two cost-effectiveness analyses, none of which found cost-effective thresholds with ICERs ranging from $\$ 201,797$ to $\$ 277,463 /$ QALY compared with BSC from US payer perspective [43, 44]. The comparability to our US price scenario is limited because these analyses used the much lower drug prices of 2017 and before. As the average cash price of a monthly regorafenib dose in April 2019 was $\$ 22,149$ according to GoodRx.com (cabozantinib \$21,581), current ICERs might be more similar.

Treating advanced medullary thyroid carcinoma with cabozantinib was incorporated in the NHS catalogue after the NICE assessed an ICER versus BSC lower than its cost-effectiveness threshold of $£ 30,000 / \mathrm{QALY}$ ( $\$ 43$, 541/QALY) [45]. In contrast, the review and economic model of Tappenden et al. found an ICER $>£ 138,000 /$ QALY (>\$200,290/QALY) for this setting [46]. Despite health economic analyses regarding cabozantinib as second-line therapy for RCC, its secondary approved indications are divergent. While three cost-effectiveness analyses and the NICE assessment found that cabozantinib dominates versus nivolumab, Deniz et al. investigated that sequences including nivolumab [29, 47-50]. After it was also approved for the first-line treatment of intermediate and high risk RCC, the NICE and Skentzou et al. assessed it as a cost-effective alternative for sunitinib and pazopanib [51, 52].

Introducing expensive new therapies into advanced disease settings as subsequent options might have a large budget impact. Underlining the controversy regarding regorafenib for the third-line treatment of advanced colorectal carcinoma in Germany, Goldstein et al. and Cho et al. reported ICERs of $\$ 900,000 /$ QALY and $\$ 395$,
223/QALY versus BSC from US payer perspective [53, 54]. The chimeric antigen receptor $T$ cell therapy for relapsed or refractory pediatric B cell leukemia with its one-time infusion cost of $\$ 475,000$ was investigated by Lin et al., estimating an ICER of $\$ 184,000 /$ QALY versus blinatumomab or chemotherapy from a US payer perspective [55]. The NICE also assessed tisagenlecleucel as not cost-effective but recommended its reimbursement by the Cancer Drugs Fund [56]. Considering all the described findings, our results rank in the upper ICER range of new therapies.

In 2019, there were multiple ongoing phase 3 trials investigating other TKIs or checkpoint inhibitors for HCC $[57,58]$. After nivolumab demonstrated effectiveness in a phase $1 / 2$ trial as second-line therapy for $\mathrm{HCC}$, a phase 3 trial for first-line therapy will finish in 2020. Additionally, the impact of the sequential or combined use of TKIs and checkpoint inhibitors will be evaluated, e.g., through a phase 3 trial of cabozantinib and atezolizumab as first-line therapy for HCC [59].

\section{Conclusion}

In conclusion, cabozantinib is an effective but not costeffective second-line therapy for HCC, as evaluated in two different healthcare systems. Our primary costeffectiveness threshold was not achieved in our base cases or almost all our scenarios. The German model had a higher probability to reach the cost-effectiveness thresholds than the US model caused by the much higher drug prices. The main cost driver is the cabozantinib drug price, and the highest uncertainty arises from QoL inputs.

\section{Supplementary information}

Supplementary information accompanies this paper at https://doi.org/10. 1186/s12876-020-01241-y.

Additional file 1 Supporting data file. This excel file contains cited supporting information and supplementary material.

\section{Abbreviations}

HCC: hepatocellular carcinoma; OS: overall survival; EMA: European Medicines Agency; GBA: Federal Joint Committee; SHI: statutory health insurances; IQWiG: German Institute for Quality and Efficiency in Health Care; 
TKI: tyrosine kinase inhibitor; VEGFR: vascular endothelial growth factor receptor; MET: hepatocyte growth factor receptor; RCC: renal cell carcinomas; PFS: progression-free survival; BSC: best supportive care; ICER: incremental cost-effectiveness ratio; LY: life year; QALY: quality-adjusted life year; GDP: gross domestic product; QoL: quality of life; AE: adverse event; NICE: British National Institute for Health and Care Excellence; DRG: diagnosis related groups; AMNOG: Pharmaceuticals Market Reorganization Act; NHS: National Health Service

\section{Acknowledgements}

Not applicable.

\section{Authors' contributions}

MS: study concept and design; acquisition of data; analysis and interpretation of data; statistical analysis; drafting and critical revision of the manuscript. MH: study concept and design; interpretation of data and critical revision of the manuscript. SU: study concept and design; critical revision of the manuscript. HA: study concept and design; acquisition of data; interpretation of data; study supervision and critical revision of the manuscript. All authors read and approved the final manuscript.

\section{Funding}

The authors declare that they have not received any funding.

\section{Availability of data and materials}

All data generated or analyzed during this study are included in this published article and its supplementary information files.

\section{Ethics approval and consent to participate}

Not applicable.

\section{Consent for publication}

Not applicable.

\section{Competing interests}

The authors declare that they have no competing interests.

\section{Author details \\ ${ }^{1}$ Faculty of Medicine, Friedrich Schiller University Jena, Jena, Germany. ${ }^{2}$ Center for Sepsis Control and Care (CSCC), Jena University Hospital, Jena, Germany. ${ }^{3}$ Hospital Pharmacy, Jena University Hospital, Jena, Germany. ${ }^{4}$ Department of General, Visceral and Vascular Surgery, Jena University Hospital, Jena, Germany.}

Received: 17 February 2020 Accepted: 26 March 2020

Published online: 21 April 2020

\section{References}

1. Baecker A, Liu X, La Vecchia C, Zhang ZF. Worldwide incidence of hepatocellular carcinoma cases attributable to major risk factors. Eur J Cancer Prev. 2018;27(3):205-12.

2. OECD. Population (indicator). OECD iLibrary. 2020. https://doi.org/10.1787/ d434f82b-en. Accessed 11 Feb 2020.

3. Barnes B, Kraywinkel K, Nowossadeck E, Schönfeld I, Starker A, Wienecke A, et al. Bericht zum Krebsgeschehen in Deutschland 2016. Berlin: Robert Koch-Institut; 2016. https://doi.org/10.17886/rkipubl-2016-014.

4. Malek NP, Schmidt S, Huber P, Manns MP, Greten TF. The diagnosis and treatment of hepatocellular carcinoma. Dtsch Arztebl Int. 2014;111(7):101-6.

5. Llovet JM, Decaens T, Raoul JL, Boucher E, Kudo M, Chang C, et al. Brivanib in patients with advanced hepatocellular carcinoma who were intolerant to sorafenib or for whom sorafenib failed: results from the randomized phase III BRISK-PS study. J Clin Oncol. 2013;31(28):3509-16.

6. Zhu AX, Kudo M, Assenat E, Cattan S, Kang Y-K, Lim HY, et al. EVOLVE-1: Phase 3 study of everolimus for advanced HCC that progressed during or after sorafenib. J Clin Oncol. 2014;32(3_suppl):172.

7. Bruix J, Qin S, Merle P, Granito A, Huang Y-H, Bodoky G, et al. Regorafenib for patients with hepatocellular carcinoma who progressed on sorafenib treatment (RESORCE): a randomised, double-blind, placebo-controlled, phase 3 trial. Lancet. 2017;389(10064):56-66.

8. Hillienhof A. Regorafenib: Onkologen kritisieren Marktrücknahme. Dtsch Arztebl Int. 2016;797(131):17.
9. IQWiG. Cabozantinib (hepatozelluläres Karzinom) - Nutzenbewertung gemäß § 35a SGB V - Dossierbewertung. 2019. Accessed 11 Feb 2020

10. Abou-Alfa GK, Meyer T, Cheng A-L, El-Khoueiry AB, Rimassa L, Ryoo B-Y, et al. Cabozantinib in patients with advanced and progressing hepatocellular carcinoma. N Engl J Med. 2018;379(1):54-63.

11. ClinicalTrials.gov. Study of Cabozantinib (XL184) vs Placebo in Subjects With Hepatocellular Carcinoma Who Have Received Prior Sorafenib (CELESTIAL) 2019. https://clinicaltrials.gov/ct2/show/NCT01908426. Accessed 11 Feb 2020.

12. Braithwaite RS, Meltzer DO, King JT Jr, Leslie D, Roberts MS. What does the value of modern medicine say about the $\$ 50,000$ per quality-adjusted lifeyear decision rule? Med Care. 2008;46(4):349-56.

13. IQWiG. Allgemeine Methoden, Version 5.0. 2017. https://www.iqwig.de/ download/Allgemeine-Methoden_Version-5-0.pdf. Accessed 11 Feb 2020.

14. IPSEN Pharma GmbH. Dossier zur Nutzenbewertung gemäß § 35a SGB V Cabozantinib-L-malat (Cabomety $x^{\oplus}$ )Modul 4 C Behandlung des Leberzellkarzinoms (HCC) bei Erwachsenen, die zuvor mit Sorafenib behandelt wurden Medizinischer Nutzen und medizinischer Zusatznutzen, Patientengruppen mit therapeutisch bedeutsamem Zusatznutzen. 2018. https://www.g-ba.de/downloads/92-975-2818/2018-12-10_Modul4C_ Cabozantinib.pdf. Accessed 11 Feb 2020.

15. Abou-Alfa GK, Meyer T, Cheng A-L, El-Khoueiry AB, Rimassa L, Ryoo B-Y, et al. Protocol for: Abou-Alfa GK, Meyer T, Cheng A-L, et al. Cabozantinib in patients with advanced and progressing Hepatocellular Carcinoma. N Engl J Med. 2018. https://www.nejm.org/doi/suppl/10.1056/NEJMoa1717002/ suppl_file/nejmoa1717002_protocol.pdf. Accessed 11 Feb 2020.

16. Federal Statistical Office of Germany. Sozialleistungen Angaben zur Krankenversicherung (Ergebnisse des Mikrozensus). 2016. https://www. destatis.de/Migration/DE/Publikationen/Thematisch/Bevoelkerung/ HaushalteMikrozensus/KrankenversicherungMikrozensus.html. Accessed 11 Feb 2020

17. Berchick ER, Barnett JC, Upton RD. Health insurance coverage in the United States: 2018. Washington, DC: U.S. Government Census Bureau; 2019. https:/www.census.gov/content/dam/Census/library/publications/2019/ demo/p60-267.pdf. Accessed 11 Feb 2020.

18. Ishak KJ, Kreif N, Benedict A, Muszbek N. Overview of parametric survival analysis for health-economic applications. Pharmacoeconomics. 2013;31(8): 663-75.

19. Abou-Alfa GK, Mollon P, Meyer T, Cheng A-L, El-Khoueiry AB, Kelley RK, et al. Quality-adjusted life years assessment using cabozantinib for patients with advanced hepatocellular carcinoma (aHCC) in the CELESTIAL trial. J Clin Oncol. 2019;37(4_suppl):207.

20. Thompson Coon J, Hoyle M, Green C, Liu Z, Welch K, Moxham T, et al. Bevacizumab, sorafenib tosylate, sunitinib and temsirolimus for renal cell carcinoma: a systematic review and economic evaluation. Health Technol Assess. 2010;14(2):1-184 iii-iv.

21. National Institute for Health and Care Excellence. Final appraisal determination Sorafenib for the treatment of advanced hepatocellular carcinoma. 2017. https://www.nice.org.uk/guidance/ta474/documents/finalappraisal-determination-document. Accessed 11 Feb 2020.

22. Camma C, Cabibbo G, Petta S, Enea M, lavarone M, Grieco A, et al. Costeffectiveness of sorafenib treatment in field practice for patients with hepatocellular carcinoma. Hepatology. 2013;57(3):1046-54.

23. Bruix J, Merle P, Granito A, Huang YH, Bodoky G, Yokosuka O, et al. Efficacy, safety, and health-related quality of life (HRQoL) of regorafenib in patients with hepatocellular carcinoma (HCC) progressing on sorafenib: Results of the international, double-blind phase 3 RESORCE trial. Ann Oncol. 2016;27: vi564. https://doi.org/10.1093/annonc/mdw435.19.

24. OECD. Purchasing power parities (PPP) (indicator). OECD iLibrary. 2020. https://doi.org/10.1787/1290ee5a-en. Accessed 11 Feb 2020.

25. National Association of Statutory Health Insurance Physicians. Einheitlicher Bewertungsmaßstab (EBM) Stand: 1. Quartal 2019. 2019. https://www.kbv.de/ media/sp/EBM_Gesamt__Stand_1._Quartal_2019.pdf. Accessed 3 April 2020.

26. Tumeh JW, Moore SG, Shapiro R, Flowers CR. Practical approach for using Medicare data to estimate costs for cost-effectiveness analysis. Expert Rev Pharmacoecon Outcomes Res. 2005;5(2):153-62.

27. Leitlinienprogramm Onkologie (Deutsche Krebsgesellschaft, Deutsche Krebshilfe, AWMF). Diagnostik und Therapie des hepatozellulären Karzinoms, Langversion 1.0, AWMF Registrierungsnummer: 032-053OL. 2013. https:/ www.leitlinienprogramm-onkologie.de/fileadmin/user_upload/Downloads/ Leitlinien/HCC/S3-HCC-OL-Langversion-V1.0.pdf. Accessed 11 Feb 2020. 
28. OECD. Gross domestic product (indicator): OECD iLibrary; 2020. https://doi. org/10.1787/4537dc58-en. Accessed 11 Feb 2020.

29. Meng J, Lister J, Vataire AL, Casciano R, Dinet J. Cost-effectiveness comparison of cabozantinib with everolimus, axitinib, and nivolumab in the treatment of advanced renal cell carcinoma following the failure of prior therapy in England. Clinicoecon Outcomes Res. 2018;10:243-50.

30. Kobayashi M, Kudo M, Izumi N, Kaneko S, Azuma M, Copher R, et al. Costeffectiveness analysis of lenvatinib treatment for patients with unresectable hepatocellular carcinoma (uHCC) compared with sorafenib in Japan. J Gastroenterol. 2019;54(6):558-70.

31. Lloyd A, Nafees B, Narewska J, Dewilde S, Watkins J. Health state utilities for metastatic breast cancer. Br J Cancer. 2006;95(6):683-90.

32. Ahlert M, Breyer F, Schwettmann L. How You Ask Is What You Get: Willingness-to-Pay for a QALY in Germany. DIW Berlin Discussion papers. 2014. https://www.diw.de/documents/publikationen/73/diw_01.c.465601.de/ dp1384.pdf. Accessed 11 Feb 2020.

33. National Institute for Health and Care Excellence. Cabozantinib for previously treated advanced hepatocellular carcinoma (terminated appraisal). 2019. https://www.nice.org.uk/guidance/ta582. Accessed 11 Feb 2020.

34. NHS England. Appraisal and funding of Cancer drugs from July 2016. 2016. https://www.england.nhs.uk/wp-content/uploads/2013/04/cdf-sop.pdf. Accessed 11 Feb 2020.

35. NHS England. National Cancer Drugs Fund List, ver1.158. 2020. https://www. england.nhs.uk/wp-content/uploads/2020/01/NationalCDF_List_ver1.15 8_-15012020_MASTER.pdf. Accessed 14 Feb 2020.

36. Shlomai A, Leshno M, Goldstein DA. Cabozantinib for patients with advanced hepatocellular carcinoma: a cost-effectiveness analysis. Ther Adv Gastroenterol. 2019;12:1756284819878304.

37. Liao W, Huang J, Hutton D, Zhu G, Wu Q, Wen F, et al. Cost-effectiveness analysis of cabozantinib as second-line therapy in advanced hepatocellular carcinoma. Liver Int. 2019:39(12):2408-16.

38. Soto-Perez-de-Celis E, Aguiar PN, Cordon ML, Chavarri-Guerra Y, Lopes GL. Cost-effectiveness of Cabozantinib in the second-line treatment of advanced hepatocellular carcinoma. J Natl Compr Cancer Netw. 2019;17(6): 669-75.

39. OECD. Health spending (indicator): OECD iLibrary; 2020. https://doi.org/10. 1787/8643de7e-en. Accessed 11 Feb 2020

40. IQVIA. IQVIA Marktbericht Entwicklung des deutschen Pharmamarktes im ersten Halbjahr 2019. 2019. https:/www.iqvia.com/de-de/locations/ germany/publikationen/marktbericht. Accessed 11 Feb 2020.

41. Bundesvereinigung Deutscher Apotheker. Zahlen, Daten, Fakten 2019. Die Apotheke. 2019; https://www.abda.de/fileadmin/user_upload/assets/ZDF/ ZDF_2019/ABDA_ZDF_2019_Brosch.pdf. Accessed 11 Feb 2020.

42. US Bureau of Labor Statistics. Prescription drugs in U.S. city average, all urban consumers, seasonally adjusted. 2020. https://data.bls.gov/timeseries/ CUSR0000SEMF01?output_view=pct_3mths. Accessed 16 Jan 2020.

43. Parikh ND, Singal AG, Hutton DW. Cost effectiveness of regorafenib as second-line therapy for patients with advanced hepatocellular carcinoma. Cancer. 2017;123(19):3725-31.

44. Shlomai A, Leshno M, Goldstein DA. Regorafenib treatment for patients with hepatocellular carcinoma who progressed on sorafenib-a costeffectiveness analysis. PLoS One. 2018;13(11):e0207132.

45. National institute for Health and Care Excellence. Final appraisal determination Cabozantinib for treating medullary thyroid cancer. 2018. https:/www.nice.org.uk/guidance/ta516/documents/final-appraisaldetermination-document. Accessed 11 Feb 2020

46. Tappenden P, Carroll C, Hamilton J, Kaltenthaler E, Wong R, Wadsley J, et al. Cabozantinib and vandetanib for unresectable locally advanced or metastatic medullary thyroid cancer: a systematic review and economic model. Health Technol Assess. 2019;23(8):1-144.

47. Lister J, Vataire A, Amzal B, Dinet J, Meng J, Karcher H, et al. Costeffectiveness in England of Cabozantinib for patients with advanced renal cell carcinoma (ARCC) after failure of prior therapy. Value Health. 2017;20(9): A441.

48. Edwards SJ, Wakefield V, Cain P, Karner C, Kew K, Bacelar M, et al. Axitinib, cabozantinib, everolimus, nivolumab, sunitinib and best supportive care in previously treated renal cell carcinoma: a systematic review and economic evaluation. Health Technol Assess. 2018;22(6):1-278.

49. National Institute for Health and Care Excellence. Cabozantinib for previously treated advanced renal cell carcinomaTechnology appraisal guidance. 2017. https://www.nice.org.uk/guidance/ta463/resources/ cabozantinib-for-previously-treated-advanced-renal-cell-carcinoma-pdf-826 04903877061. Accessed 11 Feb 2020.

50. Deniz B, Ambavane A, Yang S, Altincatal A, Doan J, Rao S, et al. Treatment sequences for advanced renal cell carcinoma: a health economic assessment. PLoS One. 2019;14(8):e0215761.

51. National institute for Health and Care Excellence. Final appraisal document Cabozantinib for untreated advanced renal cell carcinoma. 2018. https:// www.nice.org.uk/guidance/ta542/documents/final-appraisal-determinationdocument. Accessed 11 Feb 2020.

52. Skentzou E, Meng J, Lister J, Gray L. Pcn94 - cost-effectiveness of Cabozantinib versus Sunitinib or Pazopanib as first-line treatment of patients with advanced renal cell carcinoma in the Uk. Value Health. 2018; 21:S30.

53. Goldstein DA, Ahmad BB, Chen Q, Ayer T, Howard DH, Lipscomb J, et al. Cost-effectiveness analysis of Regorafenib for metastatic colorectal Cancer. J Clin Oncol. 2015;33(32):3727-32.

54. Cho SK, Hay JW, Barzi A. Cost-effectiveness analysis of Regorafenib and TAS102 in refractory metastatic colorectal Cancer in the United States. Clin Colorectal Cancer. 2018;17(4):e751-e61.

55. Lin JK, Lerman BJ, Barnes Jl, Boursiquot BC, Tan YJ, Robinson AQL, et al. Cost effectiveness of chimeric antigen receptor T-cell therapy in relapsed or refractory pediatric B-cell acute lymphoblastic leukemia. J Clin Oncol. 2018; 36(32):3192-202

56. National institute for Health and Care Excellence. Final appraisal document Tisagenlecleucel for treating relapsed or refractory B-cell acute lymphoblastic leukaemia in people aged up to 25 years. 2018. https://www. nice.org.uk/guidance/ta554/documents/final-appraisal-determinationdocument. Accessed 11 Feb 2020.

57. ClinicalTrials.gov. Efficacy and Safety of Donafenib in Patients With Advanced Hepatocellular Carcinoma. 2019. https://clinicaltrials.gov/ct2/ show/NCT02645981. Accessed 11 Feb 2020.

58. ClinicalTrials.gov. Efficacy and Tolerability of ABT-869 Versus Sorafenib in Advanced Hepatocellular Carcinoma (HCC). 2019. https://clinicaltrials.gov/ ct2/show/NCT01009593. Accessed 11 Feb 2020.

59. ClinicalTrials.gov. Study of Cabozantinib in Combination With Atezolizumab Versus Sorafenib in Subjects With Advanced HCC Who Have Not Received Previous Systemic Anticancer Therapy (COSMIC-312). 2019. https:// clinicaltrials.gov/ct2/show/NCT03755791. Accessed 11 Feb 2020

\section{Publisher's Note}

Springer Nature remains neutral with regard to jurisdictional claims in published maps and institutional affiliations.

Ready to submit your research? Choose BMC and benefit from:

- fast, convenient online submission

- thorough peer review by experienced researchers in your field

- rapid publication on acceptance

- support for research data, including large and complex data types

- gold Open Access which fosters wider collaboration and increased citations

- maximum visibility for your research: over $100 \mathrm{M}$ website views per year

At BMC, research is always in progress.

Learn more biomedcentral.com/submissions 